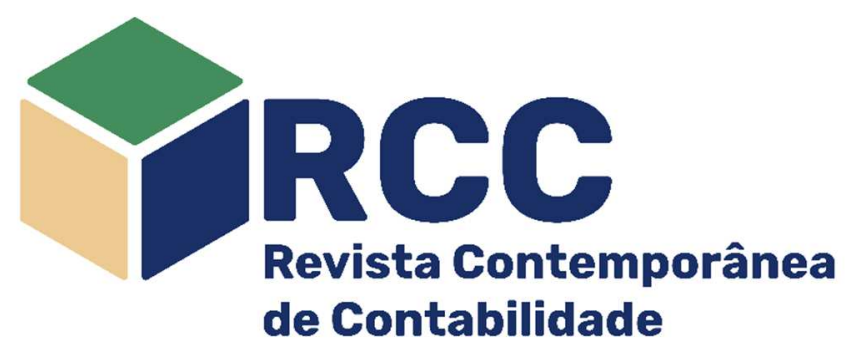

\title{
Influência da governança corporativa na assimetria de informação: uma comparação entre empresas brasileiras e americanas
}

\author{
Influence of corporate governance on information asymmetry: a comparison between Brazilian and \\ American companies
}

\begin{abstract}
Influencia del gobierno corporativo en la asimetría de la información: una comparación entre empresas brasileñas y estadounidenses
\end{abstract}

\author{
Caroline Keidann Soschinski ${ }^{\star}$ \\ Mestre em Ciências Contábeis (FURB), \\ Blumenau/SC, Brasil \\ csoschinski@furb.br \\ https://orcid.org/0000-0002-0135-0729 (1) \\ Nadia Mar Bogoni \\ Mestre em Ciências Contábeis (FURB), \\ Blumenau/SC, Brasil \\ nadiabogoni@hotmail.com \\ https://orcid.org/0000-0002-8033-7505
}

Daiani Schlup Mestre em Ciências Contábeis (FURB), Blumenau/SC, Brasil daianischlup@gmail.com https://orcid.org/0000-0002-8052-6250 (i)

Paulo Roberto da Cunha Doutor em Ciências Contábeis e Administração (FURB) Blumenau/SC, Brasil pauloccsa@furb.br https://orcid.org/0000-0001-5805-9329

Endereço do contato principal para correspondência* Rua Antônio da Veiga, 140, Sala D202, Itoupava Seca, CEP: 89.030-903 - Blumenau/SC, Brasil

\section{Resumo}

Esta pesquisa analisou a relação entre dimensões de governança corporativa (GC) e assimetria informacional entre gestores e investidores. Foram analisadas 81 empresas brasileiras e 98 americanas, listadas no lbrx 100 e no S\&P100, respectivamente, durante o período de 2012 a 2016. Evidenciou-se que a GC, de forma geral, relaciona-se negativamente à assimetria informacional no cenário brasileiro, mas não no americano. Para melhor compreender esse resultado, a GC foi analisada por suas dimensões isoladamente, o que demonstrou que nos Estados Unidos as práticas de gestão relacionam-se à menor assimetria informacional, enquanto que no Brasil as práticas relacionadas as estratégias de integração relacionam-se à menor assimetria informacional. Desta forma, estes resultados sugerem que diferentes mecanismos de GC tem diferentes implicações em cenário brasileiro e americano, o que contribui no sentido de orientar gestores a adequar práticas de GC ao contexto de seu país, de modo a minimizar a assimetria informacional de maneira eficaz. Palavras-chave: Governança Corporativa; Assimetria de Informação; Brasil; Estados Unidos

\begin{abstract}
This research analyzed the relationship between dimensions of corporate governance (CG) and informational asymmetry between managers and investors. We analyzed 81 Brazilian and 98 American companies, listed on the Ibrx100 and S \& P100, respectively, during the period from 2012 to 2016. It was evidenced that CG, in general, is negatively related to informational asymmetry in the Brazilian scenario, but not in the American. To better understand this result, CG was analyzed for its dimensions in isolation, which showed that in the United States management practices are related to the smallest information asymmetry, while in Brazil practices related to integration strategies are related to the smallest. informational asymmetry. Thus, these results suggest that different CG mechanisms have different implications in the Brazilian and American scenario, which contributes to guide managers to adapt CG practices to the context of their country, so as to minimize informational asymmetry effectively.
\end{abstract}

Keywords: Corporate Governance; Information Asymmetry; Brazil; U.S. 


\section{Resumen}

Esta investigación analizó la relación entre las dimensiones del gobierno corporativo (GC) y la asimetría informativa entre gerentes e inversores. Analizamos 81 empresas brasileñas y 98 estadounidenses, incluidas en el lbrx100 y S \& P100, respectivamente, durante el período de 2012 a 2016 . Se evidenció que GC, en general, está negativamente relacionado con la asimetría informativa en el escenario brasileño, pero no americano para comprender mejor este resultado, GC fue analizado por sus dimensiones de forma aislada, lo que mostró que en los Estados Unidos las prácticas de gestión están relacionadas con la asimetría de información más pequeña, mientras que en Brasil las prácticas relacionadas con las estrategias de integración están relacionadas con las más pequeñas. asimetría informacional. Por lo tanto, estos resultados sugieren que diferentes mecanismos de GC tienen diferentes implicaciones en el escenario brasileño y estadounidense, lo que contribuye a guiar a los gerentes a adaptar las prácticas de GC al contexto de su país, a fin de minimizar la asimetría informativa de manera efectiva.

Palabras clave: Gobierno corporativo; Asimetría de la información; Brasil; Estados Unidos

\section{Introdução}

O entendimento sobre o que compreende a governança corporativa (GC), de acordo com Gillan (2006), é diferente ao redor do mundo, o que pode decorrer de aspectos sociais, econômicos e culturais que influenciam essas práticas. De modo geral, a GC pode ser definida como um conjunto de práticas e normas realizadas com intuito de assegurar os interesses de todos os envolvidos nos resultados da companhia (PIRES; MACAGNAN, 2013).

De acordo com Pires e Macagnan (2013), a GC seria mais que um sistema de regulação da relação entre a propriedade (interesses dos acionistas) e o controle (interesses da administração ou gestão), proporcionando também à organização uma maior transparência em suas operações e eficiência em seus processos internos e externos. Segundo Vieira e Mendes (2004), a GC envolve também a minimização da assimetria de informação existente entre a empresa e os diversos agentes envolvidos nela.

Assim, conforme argumentam Vieira e Mendes (2004), uma maior transparência de informações pode levar a redução do custo de capital, na medida em que o risco pode ser melhor avaliado. Deste modo, de acordo com os autores, os acionistas se sentem mais dispostos a investir na organização, visto que tendem a acreditar que os gestores não utilizarão a assimetria de informação para proveito próprio.

A assimetria de informação tem sido discutida quanto a separação entre a propriedade e o controle do capital das organizações, o que pode gerar conflitos de interesses (JENSEN; MECKLING, 1976). Tais conflitos podem levar a diversas situações, como o acionista majoritário fazer uso de informações privilegiadas em benefício próprio durante a negociação com ações da firma. Ressalta-se ainda que, além do acionista majoritário, qualquer participante do mercado de capitais pode ser insider em negociação de títulos e valores mobiliários, por usar informações privilegiadas sobre o emitente da ação (MARTINS; PAULO, 2014).

$\mathrm{Na}$ literatura é possível encontrar alguns estudos relacionados a assimetria informacional. As pesquisas de Kanagaretnan, Lobo e Whalen (2007) e de Pires e Macagnan (2013) investigaram como a GC pode ser um fator responsável por minimizar a assimetria de informação. O estudo de Martins e Paulo (2014) analisou as relações existentes entre assimetria de informação na negociação das ações, as características econômicas e a GC, e, Albanez e Valle (2009) investigaram a relação entre assimetria de informação e a estrutura de capital.

No entanto, existem divergências nos resultados de pesquisas envolvendo a relação entre GC e a assimetria de informação. Pesquisas como a de Antunes e Mendonça (2008) e Antunes et al. (2013) evidenciaram que maiores níveis de GC não necessariamente estão relacionados à menor assimetria informacional, enquanto que Armstrong, Guay e Weber (2010) afirmam que boas práticas de GC são capazes de reduzir a assimetria informacional.

Contudo, além das divergências de resultados empíricos evidenciadas na literatura, observa-se ainda que são escassas as evidências sobre o impacto de mecanismo de GC na assimetria informacional em países emergentes e desenvolvidos. Elfeky (2017) ressalta que muitos pesquisadores têm investigado a GC em países desenvolvidos, enquanto que menor atenção tem sido dada a países em desenvolvimento. Por isso, e atrelado ao exposto por Gillan (2006) de que diferentes mecanismos podem possuir papeis diferentes quanto a redução da assimetria informacional em contextos distintos, percebe-se a necessidade de investigações também em países em desenvolvimento, ou ainda, em ambos os contextos.

Recentemente, Elfeky (2017) destacou que investigações comparativas entre países desenvolvidos e em desenvolvimento seria interessante por uma séria de razões. Primeiro, o comércio e as práticas de investimentos internacionais, assim como a globalização estão criando grandes pressões para 0 desenvolvimento da GC em países emergentes. Segundo, os países emergentes tendem a imitar as práticas realizadas em países desenvolvidos, apesar de estudos como o de Rabelo e Vasconcelos (2002) enfatizarem a diferença entre os fatores que levam à necessidade de GC nos países em desenvolvimento e desenvolvidos. Por fim, embora possa haver uma crescente convergência entre as regulamentações de GC nacionais e internacionais, há também um grande desvio das práticas e conteúdo de divulgação entre países. 
Diante do exposto na literatura e por compreender a importância da GC na redução da assimetria informacional tanto em países emergentes quanto desenvolvidos, apresenta-se a seguinte questão de pesquisa: Qual a influência da GC na assimetria de informação em empresas brasileiras e americanas? Por conseguinte, o objetivo da pesquisa é analisar a influência da GC na assimetria de informação em empresas localizadas nestes dois contextos.

A escolha do Brasil e Estados Unidos da América (EUA) como contextos de análise deste estudo, justifica-se de acordo com Oliveira et al. (2013), pois o Brasil apesar de ser um país emergente, tem grande destaque no cenário mundial, sendo considerado em inúmeras pesquisas como uma das 15 maiores potências da atualidade. Já no que tange a escolha dos EUA, levou-se em consideração o fato deste ter destaque e ser uma potência inquestionável no cenário econômico mundial (VIANA JÚNIOR; PONTE, 2016). Deste modo, utilizar um país com uma grande potência econômica, tal como EUA, e compará-lo com o Brasil sendo um país emergente, realça o contraste desses países centrando-se na dissemelhança dos mesmos.

A principal contribuição do trabalho centra-se na análise da influência da GC na assimetria informacional de empresas brasileiras e americanas, o que possibilita uma análise comparativa dos resultados encontrados com pesquisas realizadas em outros países, o que contribui para a literatura inerente ao tema. Contribui-se também no sentido de prover evidências sobre a GC por meio da utilização de métricas padrões que capturam diferentes mecanismos (de gestão, de acionistas e estratégicos) e que são adotadas por empresas de todo o mundo e disponibilizadas pela base de dados internacional Thomson Reuters Eikon.

De maneira prática, contribui-se ainda por apresentar evidências às organizações, responsáveis por auxiliá-las na redução da assimetria informacional, o que se considera uma questão importante, uma vez que empresas brasileiras, assim como empresas americanas estão sujeitas a turbulências econômicas capazes de prejudicar o ambiente econômico como um todo, se não possuírem controles e mecanismos responsáveis por controlar conflitos de agência.

Por fim, contribui-se com investidores e stakeholders de maneira geral, pois as evidências propiciam subsídio para a tomada de decisões. Tem-se que mecanismos de GC representam maior transparência, 0 que impacta na redução do custo de capital e gera maior confiabilidade das partes interessadas nas empresas, por entenderem que se as empresas investem em mecanismos de GC, tendem a agir em prol da organização como um todo.

\section{Referencial Teórico}

\subsection{Governança Corporativa}

A GC é caracterizada como um sistema pelo qual as empresas e demais organizações são dirigidas, monitoradas e incentivadas, envolvendo os relacionamentos entre sócios, conselho de administração, diretoria, órgãos de fiscalização e controle e demais partes interessadas (IBGC, 2015). As boas práticas de GC têm por objetivo converter os princípios básicos de governança em recomendações objetivas que alinhem todos os interesses das partes envolvidas, tendo como finalidade preservar e otimizar o valor econômico de longo prazo da organização, facilitando seu acesso a recursos e contribuindo para a qualidade da gestão da organização, sua longevidade e o bem comum (IBGC, 2015).

Na perspectiva de Gillan (2006), a GC está relacionada com um conjunto de leis, regras e fatores que controlam as operações de uma empresa. Porém, o autor chama atenção para o fato de a governança apresentar conceitos diferentes ao redor do mundo em virtude de influências advindas de aspectos sociais, econômicos e culturais. Para Bushman e Smith (2001), a GC é tratada de forma diversificada nos diferentes países devido às particularidades de cada mercado, que podem ser determinadas pela sua legislação, sistema regulatório, organização interna de trabalho, instituições de mercado e estrutura de propriedade do país.

Muito embora a GC possa ser tratada de forma distinta em diferentes países, seu foco continua sendo em minimizar os problemas de agência, buscando assegurar que os acionistas recebam informações confiáveis sobre o valor da empresa (BUSHMAN; SMITH, 2001). Nesse sentido, Shleifer e Vishny (1997) argumentam que a GC deve contemplar a adoção de mecanismos pelos quais os fornecedores de capitais tenham garantias que irão obter um retorno adequado para os seus investimentos, visando em especial, minimizar os conflitos de agência entre os provedores de capital das organizações.

De acordo com o IBGC (2015), as organizações brasileiras, na busca de se tornarem mais competitivas e de criarem um ambiente propício para a recepção de capital, passaram a adotar boas práticas de GC, as quais tem como seus principais pilares a transparência, prestação de contas, equidade, ética, cumprimento das leis e independência dos conselhos.

Um sistema de GC de alta performance influencia o mercado de capitais, tornando-se um dos fatores determinantes para o crescimento econômico de uma nação, à medida que fortalece as empresas, reforça as competências, amplia as bases estratégicas para criação de valor e harmonização de interesses, tornando os negócios seguros e menos expostos a riscos internos e externos (SILVEIRA, 2004). Na mesma linha, Sheikh e Wang (2012) estabelecem que elevado nível de GC permite o aumento do desempenho da 
organização, por meio da criação e manutenção de uma cultura corporativa que motiva a administração a tomar decisões que maximizem a riqueza dos acionistas.

Os principais pontos que certificam a empresa com boas práticas de GC são a boa qualidade e quantidade das informações apresentadas ao mercado, bem como a segurança institucional (SHLEIFER; VISHNY, 1997). Dessa forma, as boas práticas surgem como um instrumento para buscar a superação do clássico problema da teoria de agência (conflito de interesses entre as partes interessadas) e são enquadradas como um mecanismo de controle para inibir ou limitar os agentes (administradores) a agirem em interesse próprio e, simultaneamente, reduzir problemas com a assimetria de informações (IBGC, 2015).

Segundo Moreiras (2010), as práticas de GC podem reduzir as informações assimétricas dentro das organizações e diminuir o custo de agência, tornando a relação entre o administrador e o acionista mais transparente. Na mesma linha, Anuchitworawong (2010) estabelece que quanto mais informações forem divulgadas, menores incidências de assimetria de informação existirão entre a administração, os investidores e demais stakeholders. Boas práticas de GC podem ajudar a atenuar os problemas de agência entre empresas e investidores, o que reduz, indiretamente, o custo de capital (MOREIRAS, 2010; ANUCHITWORAWONG, 2010).

Nesse contexto, as relações entre GC e assimetria de informações vêm ganhando espaço nas pesquisas acadêmicas, uma vez que são consideradas canais que promovem a dinâmica na promoção do desenvolvimento dos mercados financeiros e, consequentemente, das empresas que atuam nesses mercados (BARBEDO; SILVA; LEAL, 2009; ALBANEZ; VALLE, 2009; OLIVEIRA; PAULO; MARTINS, 2013; MENSI et al., 2016).

\subsection{Hipótese}

Os efeitos da assimetria de informação foram inicialmente discutidos por Akerlof (1978). Para o autor, a assimetria de informação está relacionada às relações de troca e com a existência de mercados ineficientes, os quais permitem a possibilidade de maiores ganhos para alguns e menores para outros. Ou seja, a assimetria de informação ocorre quando um dos participantes de um negócio possui melhores informações do que outros (AKERLOF, 1978).

A assimetria de informações tem sido abordada a partir da Teoria da Agência, inicialmente discutida por Berle e Means (1932) e posteriormente por Jensen e Meckling (1976). Essa teoria explica a separação entre a propriedade e o controle de capital das empresas, os quais, para os autores, instigam conflitos de agência. Nesse caso, os agentes internos tentam maximizar a utilidade desapropriando os ganhos dos agentes externos, os quais possuem menos acesso as informações sobre as organizações (JENSEN; MECKLING, 1976).

As boas práticas de GC proporcionam maior transparência, informações e harmonização de interesses a todos os agentes envolvidos nas organizações, minimizando a assimetria de informações existente entre empresa e stakeholders. Nessa linha, Barbedo, Silva e Leal (2009) afirmam que em mercados de mesma liquidez, quanto maior o nível de GC, menor a probabilidade de ocorrer uma operação com informação privilegiada, o que sugere que as práticas de GC ampliam o nível de informação existente no mercado, diminuindo a problemática da assimetria. Assim, a GC e a consequente redução da assimetria informacional se tornam dois importantes instrumentos para mitigação dos efeitos causados por problemas de agência (BARBEDO; SILVA; LEAL, 2009).

Dada a importância da relação existente entre a GC e a assimetria de informações, tem-se na literatura diversos estudos que buscaram analisar essa associação. Para La Porta et al. (2002) e Klapper e Love (2004), o mercado precifica a qualidade da governança evidenciada pelas empresas e a redução de assimetria de informação aumenta o valor das empresas. O estudo Kanagaretnam, Lobo e Whalen (2007) indica que as empresas com níveis mais elevados de GC têm menor assimetria de informação em torno de anúncios trimestrais de lucros.

Fauver e Naranjo (2010), por sua vez, afirmam que as empresas menos transparentes enfrentam maiores custos de agência, possuem GC mais fraca, mais problemas de assimetria de informação e acompanhamento global mais pobre. De maneira semelhante, Armstrong, Guay e Weber (2010) afirmam que boas práticas de GC são capazes de reduzir a assimetria informacional. Mais recentemente, Li et al. (2018), sugeriram que a GC pode reduzir problemas de agência como a assimetria de informação existente entre insiders (gestores) e outsiders (acionistas e stakeholders).

No Brasil, Martins e Paulo (2014) analisaram a relação entre a assimetria de informação na negociação de ações, as características econômicas e financeiras e a GC das empresas listadas no mercado de ações brasileiro em 2010 e 2011. Para os autores, a assimetria informacional na negociação de ações foi positivamente relacionada ao risco, retorno e liquidez das ações, bem como o custo do capital próprio e o tamanho das empresas. Rodrigues e Galdi (2017) investigaram se a atividade de Relação com Investidores (RI) diminuiu a assimetria informacional entre a empresa e o mercado, em empresas brasileiras, e identificaram que websites de RI mais informativos são capazes de diminuir a assimetria informacional.

No entanto, também há estudos que geraram evidências de que mecanismos de GC não foram responsáveis por minimizar contextos de informações assimétricas. Antunes e Mendonça (2008) e Antunes 
et al. (2013) apontaram que maiores níveis de GC não estão necessariamente associados à menor assimetria de informações, uma vez que os resultados dos níveis diferenciados de governança da Bolsa de Valores de São Paulo (NDGB) não afetaram a qualidade das informações contábeis.

Diante do exposto, percebe-se que, apesar de os estudos sobre a relação entre GC e assimetria de informações terem avançado em termos de investigações adicionais sobre o tema em diversos contextos, ainda há uma incongruência com relação aos resultados encontrados, o que de acordo com Gillan (2006), pode ser decorrente do fato de que diferentes mecanismos de GC podem possuir diferentes papeis quanto a minimização da assimetria informacional em cenários distintos. Além disso, menor atenção tem sido dada ao contexto de países emergentes (ELFEKY, 2017). Com base disso, esta pesquisa visa testar o impacto dos diferentes mecanismos de GC na assimetria de informação em cenário brasileiro e americano. Para isso, foi testada a seguinte hipótese:

$H_{1}$ - Há uma relação negativa entre as melhores práticas de GC e a assimetria de informação em empresas brasileiras e americanas.

\section{Procedimentos Metodológicos}

Esta pesquisa se caracteriza como descritiva, documental e quantitativa. A população do estudo correspondeu as 100 empresas do Brasil e dos Estados Unidos, listadas no índice Ibrx100 e no S\&P100, respectivamente, para fins de dar proporcionalidade às comparações e por se tratarem de empresas relevantes em ambos os cenários.

Para delinear a amostra, foram excluídas as empresas que não continham informações relacionadas as variáveis da pesquisa e as empresas que estavam a 3 desvios padrão distantes da média, por serem consideradas outliers. A amostra final correspondeu à 81 empresas brasileiras que geraram 390 observações e 98 empresas americanas que geraram 472 observações. Ambas as amostras foram analisadas durante 0 período de 2012 a 2016. Para a coleta de dados, utilizou-se do banco de dados da Thomson Reuters Eikon. As variáveis utilizadas na investigação estão apresentadas na Tabela 1.

Tabela 1 - Variáveis da pesquisa

\begin{tabular}{|c|c|c|c|c|}
\hline \multicolumn{2}{|c|}{ Variável } & Descrição & Cálculo & Autores \\
\hline \multicolumn{5}{|c|}{ Variável dependente (Assimetria de informação) } \\
\hline \multicolumn{2}{|c|}{ SpreadAno $_{\text {it }}$} & $\begin{array}{l}\text { Bid-ask spread calculado por meio da média diária de todo o } \\
\text { exercício analisado }\end{array}$ & \multirow{3}{*}{$\frac{(A s k-B i d)}{\left(\frac{A s k+B i d}{2}\right)}$} & \multirow{3}{*}{$\begin{array}{l}\text { Jiang, Habib e Hu } \\
\text { (2011); Rezende, } \\
\text { Almeida e Lemes } \\
\text { (2015). }\end{array}$} \\
\hline \multicolumn{2}{|c|}{ Spread $3 m_{\text {it }}$} & $\begin{array}{c}\text { Bid-ask spread calculado por meio da média diária de até } 3 \\
\text { meses posteriores ao exercício analisado }\end{array}$ & & \\
\hline \multicolumn{2}{|c|}{ Spread6mit } & $\begin{array}{l}\text { Bid-ask spread calculado por meio da média diária de até } 6 \\
\text { meses posteriores ao exercício analisado }\end{array}$ & & \\
\hline \multicolumn{5}{|c|}{ Variáveis independentes (Governança Corporativa) } \\
\hline \multirow{4}{*}{ 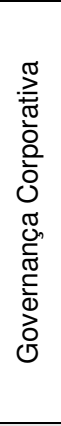 } & $\begin{array}{c}\text { Geral } \\
\left(G C \_G e r a l\right)\end{array}$ & $\begin{array}{l}\text { Reflete a governança corporativa de maneira integrada com } \\
\text { as três dimensões de gestão, acionistas e estratégias. }\end{array}$ & $\begin{array}{l}\text { (GC_Ges + } \\
\text { GC_Aci + } \\
\text { GC_Est) / } 3\end{array}$ & $\begin{array}{l}\text { Proposto pelos } \\
\text { autores. }\end{array}$ \\
\hline & $\begin{array}{l}\text { Gestão } \\
\text { (CG_Ges) }\end{array}$ & $\begin{array}{c}\text { Mede o compromisso e a eficácia de uma empresa para } \\
\text { seguir as melhores práticas e princípios de governança } \\
\text { corporativa. }\end{array}$ & \multirow{3}{*}{$\begin{array}{l}\text { Pontuação: } \\
\text { Varia de } 0 \text { a } \\
\quad 100 .\end{array}$} & \multirow{3}{*}{ Li et al. (2018). } \\
\hline & $\begin{array}{l}\text { Acionistas } \\
\text { (GC_Aci) }\end{array}$ & $\begin{array}{l}\text { Avalia a eficácia de uma empresa para a igualdade de } \\
\text { tratamento dos acionistas e o uso de dispositivos anti- } \\
\text { takeover. }\end{array}$ & & \\
\hline & $\begin{array}{l}\text { Estratégias } \\
\text { (GC_Est) }\end{array}$ & $\begin{array}{c}\text { Reflete as práticas de uma empresa para comunicar e } \\
\text { integrar as dimensões econômicas (financeiras), sociais e } \\
\text { ambientais em seus processos de tomada de decisão do dia- } \\
\text { a-dia. }\end{array}$ & & \\
\hline \multicolumn{5}{|c|}{ Variáveis independentes de controle } \\
\hline \multicolumn{2}{|c|}{ Tamanho (TAM) } & $\begin{array}{c}\text { Tamanho da empresa representado pelo ativo total da } \\
\text { empresa logaritmizado. }\end{array}$ & $\begin{array}{l}\text { LN do Ativo } \\
\text { Total. }\end{array}$ & $\begin{array}{l}\text { Doyle, Ge e McVay } \\
\text { (2007); Silva, Cunha e } \\
\text { Teixeira (2017). }\end{array}$ \\
\hline \multicolumn{2}{|c|}{$\begin{array}{l}\text { Rentabilidade do } \\
\text { Patrimônio Líquido } \\
\text { (ROE) }\end{array}$} & Rentabilidade do Patrimônio Líquido & $\begin{array}{l}\text { Lucro Líquido / } \\
\text { Patrimônio } \\
\text { Líquido }\end{array}$ & $\begin{array}{l}\text { Doyle, Ge e McVay } \\
\text { (2007); Silva, Cunha e } \\
\text { Teixeira (2017). } \\
\end{array}$ \\
\hline \multicolumn{2}{|c|}{ Endividamento (END) } & $\begin{array}{c}\text { Endividamento da empresa, representado pela soma do } \\
\text { passivo circulante, mais passivo não circulante, escalonado } \\
\text { pelo ativo total da empresa. }\end{array}$ & $\begin{array}{l}\text { (Passivo } \\
\text { Circulante }+ \\
\text { Passivo Não } \\
\text { Circulante) / } \\
\text { Ativo total }\end{array}$ & $\begin{array}{l}\text { Silva, Cunha e } \\
\text { Teixeira (2017). }\end{array}$ \\
\hline
\end{tabular}

Fonte: Dados da pesquisa.

Utilizou-se para esse estudo o cálculo do spread de três maneiras distintas. A primeira medida é referente a média do spread diário dos 12 meses, que compreende o período de 1 ano. A segunda medida é referente a média do spread dos 12 meses do período atual mais a média do spread dos 3 meses posteriores, ou seja, de janeiro, fevereiro e março do período subsequente. Por fim, a terceira medida de spread é referente 
a média do spread dos 12 meses do período atual mais o spread dos 6 meses posteriores, ou seja, de janeiro a junho do ano subsequente. Essa análise é realizada com o intuito de captar a distância temporal da assimetria da informação, considerando que estudos anteriores evidenciaram que determinados fatores refletem na assimetria de informação somente em meses posteriores ao final de um período.

Com relação às medidas de GC, vale ressaltar que nos estudos anteriores foram utilizadas como medidas de GC alguns mecanismos isolados, como por exemplo, o conselho de administração e suas características (SILVA; CUNHA; TEIXEIRA, 2017), ou o comitê de auditoria e suas características (CHANG; SUN, 2009). Todavia, atualmente a base de dados Thomson Reuters Eikon disponibilizou três dimensões de GC, referentes à gestão, aos acionistas e as estratégias, sendo que nessas dimensões estão incluídos inúmeros mecanismos de GC.

A dimensão de GC referente à gestão (GC_Ges) é composta pelo total de 56 itens que visam avaliar se a empresa possui ou não, política de funções do conselho, comitê de GC, comitê de auditoria, política de independência do conselho, política de diversidade do conselho, entre outros. A dimensão referente aos acionistas (GC_Aci) é composta por 35 itens que visam avaliar se a empresa possui ou não política de direito dos acionistas, política de direito igualitário de voto, política de engajamento dos acionistas, entre outros. A dimensão referente às estratégicas (GC_Est) é composta pelo total de 11 itens que visam avaliar se a empresa possui ou não comitê de sustentabilidade, se busca o engajamento das partes interessadas, se divulga relatório de sustentabilidade com base nas diretrizes do GRI, entre outros. Os itens que compõem cada dimensão de GC estão como anexos desta pesquisa.

Para as três dimensões, a base de dados calculou mediante metodologia própria, um score final que pode variar de 0 a 100, sendo que, quanto mais itens a empresa divulgar com relação à gestão, aos acionistas e as estratégias, mais próximo a 100 será o seu score final. Ademais, com o intuito de analisar a GC de forma integrada e abrangente, foi calculada a média dessas três dimensões de GC, formando-se assim uma dimensão geral de GC (GC_Geral).

Com relação às variáveis de controle, mediante o estudo de Silva, Cunha e Teixeira (2017), pode-se verificar que variáveis como o tamanho da empresa, a rentabilidade sobre o patrimônio líquido e o endividamento, podem influenciar na assimetria de informação, e, portanto, optou-se por utilizar essas variáveis como de controle. Além disso, para controlar as diferenças contidas entre períodos e entre setores, utilizou-se como efeito fixo os anos e setores.

A operacionalização das variáveis foi realizada mediante método estatístico de regressão linear múltipla (OLS), com erros padrões robustos, a fim de corrigir problemas de heterocedasticidade dos resíduos. Foram estimadas 6 equações, sendo que as 3 primeiras foram realizadas com o intuito de investigar a GC em sua dimensão geral (GC_Geral) e as 3 finais com o intuito de analisar a relação entre cada dimensão de GC (GC_Ges; GC_Aci; GC_Est) e a assimetria informacional. As equações 1 a 6 foram operacionalizadas para a amostra de empresas brasileiras e americanas, separadamente.

$$
\begin{aligned}
& \text { Spread_ano }_{i t}=\beta_{0}+\beta_{1} G C_{-} G_{\text {Geral }}+\beta_{2} T A M_{i t}+\beta_{3} R O E_{i t}+\beta_{4} E N D_{i t}+\sum_{\text {EfeitoFixoSetor }}+\sum_{\text {EfeitoFixoAno }}+\varepsilon_{i t} \\
& \begin{array}{l}
\text { Equação } 1 \\
\text { Spread_3mit }
\end{array} \\
& \text { Spread_3m }_{i t}=\beta_{0}+\beta_{1} G C_{-} G_{\text {Geral }}+\beta_{2}{ }_{\text {TAM }}+\beta_{3} R O E_{i t}+\beta_{4} E N D_{i t}+\sum_{\text {EfeitoFixosetor }}+\sum_{\text {EfeitoFixoAno }}+\varepsilon_{\text {it }} \\
& \text { Spread_6m }_{i t}=\beta_{0}+\beta_{1} G C_{-} G e r a l_{i t}+\beta_{2} T A M_{i t}+\beta_{3} R O E_{i t}+\beta_{4} E_{N D}+\sum_{\text {EfeitoFixosetor }}+\sum_{\text {EfeitoFixoAno }}+\varepsilon_{i t} \\
& \text { Spread_ano }_{i t}=\beta_{0}+\beta_{1} G C_{-} G e s_{i t}+\beta_{2} G C_{-} A c i_{i t}+\beta_{3} G C_{-} E s t_{i t}+\beta_{4} T A M_{i t}+\beta_{5} R O E_{i t}+\beta_{6} E N D_{i t}+ \\
& \sum_{\text {EfeitoFixoSetor }}+\sum_{\text {EfeitoFixoAno }}+\varepsilon_{\text {it }}
\end{aligned}
$$

Equação 4

$$
\begin{gathered}
\text { Spread_3m } 3 m_{i t}=\beta_{0}+\beta_{1} G C_{-} G e s_{i t}+\beta_{2} G C_{-} A c i_{i t}+\beta_{3} G C_{-} E s t_{i t}+\beta_{4} T A M_{i t}+\beta_{5} R O E_{i t}+\beta_{6} E N D_{i t}+ \\
\sum_{E f e i t o F i x o S e t o r}+\sum_{E f e i t o F i x o A n o}+\varepsilon_{i t}
\end{gathered}
$$

Equação 5

$$
\begin{gathered}
\text { Spread_6m } m_{i t}=\beta_{0}+\beta_{1} G C_{-} G e s_{i t}+\beta_{2} G C_{-} A c i_{i t}+\beta_{3} G C_{-} E s t_{i t}+\beta_{4} T A M_{i t}+\beta_{5} R O E_{i t}+\beta_{6} E N D_{i t}+ \\
\sum_{E f e i t o F i x o S e t o r}+\sum_{E f e i t o F i x o A n o}+\varepsilon_{i t}
\end{gathered}
$$

Equação 6

Em que: Spread ano $i t$, Spread_3 $3 m_{i t}$, Spread_6m $6 m_{i t}$ são as medidas de assimetria informacional no término de um ano, em 3 meses após o término do ano e em 6 meses após o término do ano, respectivamente; $G C_{-} G e r a l_{i t}$ é a medida agregada de GC, calculada pela média das dimensões de gestão, acionistas e estratégias; $G C_{-} G e s_{i t}$ representa os mecanismos de GC relacionados a gestão; $G C_{-} A c i_{i t}$ representa os mecanismos de GC relacionados ao alinhamento de interesses entre acionistas minoritários e majoritários; $G C_{-} E s t_{i t}$ representa os mecanismos de GC relacionados as estratégias; $T A M_{i t}$ é o logaritmo natural do ativo total; $R O E_{i t}$ é a rentabilidade sobre o patrimônio líquido; $E N D_{i t}$ é o endividamento; e o somatório de efeito fixo 
de setor e ano representa dummies para cada setor e cada ano. A descrição e cálculo de cada variável estão apresentadas na Tabela 1.

Antes de proceder a análise dos resultados, foram testados os pressupostos dos modelos de regressão linear múltipla. O problema de heterocedasticidade foi solucionado mediante a utilização de erros padrões robustos, o pressuposto da normalidade foi relaxado em função do número de observações, o pressuposto de multicolinearidade foi testado mediante teste VIF, presente nas tabelas de análise dos resultados, bem como o teste de Durbin Watson, que testou problemas de auto correlação dos resíduos.

\section{Análise e Discussão dos Resultados}

Apresenta-se mediante Tabela 2 a estatística descritiva das variáveis. Posteriormente, a Tabela 3 apresenta os resultados das equações 1, 2 e 3, foco dessa investigação. Por fim, a Tabela 4 apresenta uma análise acerca da GC em suas dimensões de gestão, acionistas e estratégias, referentes às equações 4,5 e 6. Ressalta-se que em todas as tabelas de análise, os dados estão divididos em empresas brasileiras e americanas.

Tabela 2 - Estatística descritiva dos resultados

\begin{tabular}{|c|c|c|c|c|c|c|c|c|c|}
\hline \multirow{2}{*}{ Variáveis } & \multicolumn{4}{|c|}{ BRA } & \multicolumn{4}{|c|}{ EUA } & \multirow[t]{2}{*}{ Teste $t$-Student } \\
\hline & Mín & Máx & Méd & DP & Mín & Máx & Méd & DP & \\
\hline SpreadAno & $-0,0238$ & 0,02423 & 0,0049 & 0,0041 & 0,0001 & 0,0005 & 0,000225 & 0,00009 & $24,97^{*}$ \\
\hline Spread_3m & $-0,0291$ & 0,0460 & 0,0042 & 0,0040 & 0,0001 & 0,0005 & 0,000224 & 0,00008 & $21,62^{*}$ \\
\hline Spread_6m & $-0,0141$ & 0,0344 & 0,0038 & 0,0030 & 0,0001 & 0,0005 & 0,000221 & 0,00008 & $26,20^{*}$ \\
\hline GC_Geral & 0,0000 & 86,0573 & 39,9549 & 24,9648 & 11,0376 & 98,1258 & 67,9309 & 17,3821 & $-19,32^{*}$ \\
\hline GC_Ges & 0,0000 & 99,4736 & 39,2315 & 31,9518 & 2,9411 & 99,9491 & 66,2897 & 25,3498 & $-13,86^{*}$ \\
\hline GC_Aci & 0,0000 & 91,8604 & 39,9695 & 32,6661 & 0,3611 & 99,8458 & 58,8443 & 27,8512 & $-9,15^{*}$ \\
\hline GC_Est & 0,0000 & 98,9361 & 40,6638 & 32,1477 & 15,7142 & 99,7872 & 78,6588 & 20,5860 & $-20,99^{*}$ \\
\hline TAM & 19,0372 & 25,5401 & 22,1030 & 1,1638 & 23,0693 & 28,5758 & 25,1651 & 1,1208 & $-39,23^{*}$ \\
\hline ROE & $-0,9423$ & 1,3675 & 0,1194 & 0,2305 & $-5,5505$ & 5,9914 & 0,2362 & 0,5912 & $-3,67^{*}$ \\
\hline END & 0,0847 & 1,4342 & 0,5860 & 0,1980 & 0,0887 & 1,2034 & 0,6540 & 0,1833 & $-5,19^{*}$ \\
\hline Obs. & \multicolumn{4}{|c|}{3} & \multicolumn{4}{|c|}{472} & \\
\hline
\end{tabular}

Legenda: * Significância a nível de 5\%; ** Significância a nível de 10\%; Min: mínimo, Máx: máximo, Méd: média, DP: Desvio-padrão, GC_Ges: Gestão, GC_Aci: Acionistas, GC_Est: Estratégias, TAM: Tamanho, ROE: Rentabilidade sobre o patrimônio líquido, END: Endividamento, Obs.: Número de observações; Para operacionalizar o teste t de médias, assim como para regressões OLS, assumiu-se o Teoria Central do Limite para o pressuposto de normalidade, isto é, a distribuição da média de uma amostra suficientemente grande tende a ser aproximadamente normal.

Fonte: Elaborado pelos autores.

Destaca-se inicialmente que a média de todas as variáveis foi testada mediante teste de médias $t$ Student, sendo que as médias se demonstraram estatisticamente diferentes para todas as variáveis comparadas (BRA x EUA). Observa-se mediante os valores médios das três medidas de assimetria de informação (Spread_Ano, Spread_3m e Spread_6m) que empresas brasileiras possuem valores significativamente maiores de assimetria de informação, representando cerca de $1000 \%$ a mais do que nas empresas americanas, tanto ao final do exercício quanto após 3 e 6 meses.

Percebe-se um comportamento semelhante entre empresas de ambos os países com relação a assimetria de informação, que vai reduzindo gradativamente após os 3 e 6 meses ao término de um período. Nota-se que tanto para empresas brasileiras quanto americanas, os períodos posteriores ao final de um ano são marcados pela redução da assimetria informacional. Tal fato pode ser decorrente de que em meses posteriores ao final de um determinado período, as empresas geralmente publicam seus relatórios e demonstrativos, o que representa mais informações divulgadas as partes interessadas, maior transparência e consequentemente, menor assimetria entre informações obtidas por gestores e acionistas.

Com relação a GC, observa-se que, enquanto a média da GC no Brasil é de 39,95 (GC_Geral), nos EUA essa média é de 67,93 (GC_Geral), aproximadamente 70\% maior nas empresas americanas. Estes resultados acerca dos indicadores de GC do Brasil, corroboram com os de Li et al. (2018), que evidenciaram a média de 30,67 de GC em empresas localizadas no Reino Unido, cuja economia se encontra em desenvolvimento, assim como a brasileira.

A dimensão de GC relacionada à gestão é a dimensão cujas empresas brasileiras possuem o menor score, ou seja, atendem ao menor número de itens relacionados ao comitê de auditoria, conselho de administração, comitê de GC, política de independência do conselho, política de diversidade do conselho, entre outros. Por outro lado, as empresas americanas possuem o menor score de GC direcionado aos 
acionistas, evidenciando menor quantidade de itens divulgados sobre política de engajamentos dos acionistas, política de direito dos acionistas, política de direito igualitário de voto, entre outros.

No que concerne as variáveis de controle, nota-se que em média as empresas americanas são significativamente maiores (TAM) do que as brasileiras, são significativamente mais rentáveis com relação ao seu patrimônio líquido (ROE) e significativamente mais endividadas (END). Com relação aos desvios das variáveis em torno da média, observa-se que para a maioria das variáveis, nos EUA há menor oscilação de valores, exceto quando se observa a rentabilidade sobre o patrimônio líquido, cujo desvio padrão se apresenta acima da média e acima do desvio-padrão das empresas brasileiras, representando assim maior oscilação de valores entre as empresas americanas.

$\mathrm{Na}$ Tabela 3, observam-se os resultados referentes as equações 1, 2 e 3. Ressalta-se que no Painel A estão dispostos os resultados referentes a equação 1 que trata do spread no final de um período, no Painel B os resultados da equação 2 que trata do spread em 3 meses após o final de um período e por fim, no Painel C os resultados da equação 3 que trata do spread em 6 meses após o final de um período.

Tabela 3 - Influência da governança corporativa na assimetria de informação Painel A: Assimetria de informação medida pelo spread no final do período.

\begin{tabular}{|c|c|c|c|c|c|c|}
\hline \multirow{3}{*}{ Variáveis } & \multicolumn{3}{|c|}{ BRA } & \multicolumn{3}{|c|}{ EUA } \\
\hline & \multicolumn{6}{|c|}{ Equação 1} \\
\hline & Coeficiente & $t$ & VIF & Coeficiente & $t$ & VIF \\
\hline Constante & $0,0305^{\star}$ & 4,55 & - & 0,0001 & 0,80 & - \\
\hline GC_Geral & $-0,0000^{*}$ & $-3,15$ & 1,59 & $-2,40 e-0$ & $-0,85$ & 1,30 \\
\hline TAM & $-0,0008^{*}$ & $-3,79$ & 2,71 & 0,0000 & 1,49 & 2,93 \\
\hline ROE & 0,0001 & 0,11 & 1,57 & $-8,82 e^{-*}$ & $-2,30$ & 1,11 \\
\hline END & $-0,0002$ & $-0,22$ & 1,72 & $-0,0000^{\star *}$ & $-1,67$ & 2,13 \\
\hline Efeito Fixo - Setor & \multicolumn{3}{|c|}{ Sim } & \multicolumn{3}{|c|}{ Sim } \\
\hline Efeito Fixo - Ano & \multicolumn{3}{|c|}{ Sim } & \multicolumn{3}{|c|}{ Sim } \\
\hline $\mathrm{R}^{2}$ & \multicolumn{3}{|c|}{0,2773} & \multicolumn{3}{|c|}{0,2953} \\
\hline ANOVA & \multicolumn{3}{|c|}{$0,0000^{*}$} & \multicolumn{3}{|c|}{$0,0000^{*}$} \\
\hline Durbin Watson & \multicolumn{3}{|c|}{1,7733} & \multicolumn{3}{|c|}{2,1893} \\
\hline Número de observações & \multicolumn{3}{|c|}{390} & \multicolumn{3}{|c|}{472} \\
\hline
\end{tabular}

\begin{tabular}{|c|c|c|c|c|c|c|}
\hline \multirow{3}{*}{ Variáveis } & \multicolumn{3}{|c|}{ BRA } & \multicolumn{3}{|c|}{ EUA } \\
\hline & \multicolumn{6}{|c|}{ Equação 2} \\
\hline & Coeficiente & $t$ & VIF & Coeficiente & $t$ & VIF \\
\hline Constante & $0,0311^{*}$ & 2,83 & - & 0,0001 & 0,76 & - \\
\hline GC_Geral & $-0,0000^{*}$ & $-4,23$ & 1,59 & $-2,54 \mathrm{e}-$ & $-0,90$ & 1,30 \\
\hline TAM & $-0,0006^{*}$ & $-4,05$ & 2,71 & 0,0000 & 1,51 & 2,93 \\
\hline ROE & 0,0005 & 0,33 & 1,57 & $-9,04 e^{*}$ & $-2,43$ & 1,11 \\
\hline END & 0,0012 & 1,62 & 1,72 & $-0,0000^{\star *}$ & $-1,69$ & 2,13 \\
\hline Efeito Fixo - Setor & \multicolumn{3}{|c|}{ Sim } & \multicolumn{3}{|c|}{ Sim } \\
\hline Efeito Fixo - Ano & \multicolumn{3}{|c|}{ Sim } & \multicolumn{3}{|c|}{ Sim } \\
\hline $\mathrm{R}^{2}$ & \multicolumn{3}{|c|}{0,3619} & \multicolumn{3}{|c|}{0,2865} \\
\hline ANOVA & \multicolumn{3}{|c|}{$0,0000^{*}$} & \multicolumn{3}{|c|}{$0,0000^{*}$} \\
\hline Durbin Watson & \multicolumn{3}{|c|}{2,022} & \multicolumn{3}{|c|}{2,1846} \\
\hline Número de observações & \multicolumn{3}{|c|}{390} & \multicolumn{3}{|c|}{472} \\
\hline \multicolumn{7}{|c|}{ Painel C: Assimetria de informação medida pelo spread em 6 meses após o final do período. } \\
\hline \multirow{3}{*}{ Variáveis } & \multicolumn{3}{|c|}{ BRA } & \multirow{2}{*}{\multicolumn{3}{|c|}{ EUA }} \\
\hline & \multicolumn{3}{|c|}{ Equação 3} & & & \\
\hline & Coeficiente & $\mathbf{t}$ & VIF & Coeficiente & $\mathbf{t}$ & VIF \\
\hline Constante & $0,0268^{*}$ & 3.35 & - & 0,0001 & 0,72 & - \\
\hline GC Geral & $-0,0000^{*}$ & -4.57 & 1,59 & $-2,49 \mathrm{e}-$ & $-0,88$ & 1,30 \\
\hline TAM & $-0,0005^{*}$ & -4.83 & 2,71 & 0,0000 & 1,55 & 2,93 \\
\hline ROE & $-0,0002$ & -0.32 & 1,57 & $-9,27 e-{ }^{*}$ & $-2,52$ & 1,11 \\
\hline END & 0,0006 & 0.90 & 1,72 & $-0,0000^{\star \star}$ & $-1,74$ & 2,13 \\
\hline Efeito Fixo - Setor & \multicolumn{3}{|c|}{ Sim } & \multicolumn{3}{|c|}{ Sim } \\
\hline Efeito Fixo - Ano & \multicolumn{3}{|c|}{ Sim } & \multicolumn{3}{|c|}{ Sim } \\
\hline $\mathrm{R}^{2}$ & \multicolumn{3}{|c|}{0,3573} & \multicolumn{3}{|c|}{0,2824} \\
\hline ANOVA & \multicolumn{3}{|c|}{$0,0000^{*}$} & \multicolumn{3}{|c|}{$0,0000^{*}$} \\
\hline Durbin Watson & \multicolumn{3}{|c|}{2,0645} & \multicolumn{3}{|c|}{2,1847} \\
\hline Número de observações & & & & & & \\
\hline
\end{tabular}

Legenda: * Significância a nível de 5\%; ** Significância a nível de 10\%; BRA: Brasil, EUA: Estados Unidos, t: Estatística t, VIF: Variance Inflation Factor, TAM: Tamanho, ROE: Rentabilidade sobre o Patrimônio líquido, END: Endividamento.

Fonte: Elaborado pelos autores.

Nota-se que o teste ANOVA é significativo em todos os modelos econométricos apresentados na Tabela 3, o que permite a inferência de resultados com base nesses modelos. Percebe-se também que 
nenhuma das variáveis apresentam problemas de multicolinearidade, o que é exposto pelo teste VIF em cada modelo. Ademais, nenhum dos modelos possuem graves problemas de auto correlação dos resíduos, o que também pode ser verificado mediante o teste Durbin Watson, que apresentou em todos os modelos valores próximos à 2. Por fim, destaca-se os baixos coeficientes apresentados na maioria dos modelos econométricos, o que pode ser decorrente de diferenças entre escalas, uma vez que a métrica de bid ask spread varia em torno de 0,0049 e a métrica de GC em torno de 39,9549. No entanto, as diferentes escalas não comprometem os resultados estatísticos, apenas limitam a comparabilidade entre as variáveis.

Nas empresas brasileiras, observa-se que a GC em sua dimensão geral (GC_Geral), apresentou-se negativamente e estatisticamente relacionada com a assimetria de informação, mensurada no término de um período e após 3 e 6 meses ao térmico de um período, resultado este esperado pela literatura. Ressalta-se que a significância foi obtida para as três variáveis de spread (Painel $A$, B e C) e por meio da análise da estatística $t$, pode-se perceber que essa relação se mostra mais forte em períodos posteriores ao final de um período (Painel B e C).

Desta forma, infere-se que empresas brasileiras com maior nível de GC tendem a possuir menor assimetria informacional ou que empresas com menor nível de GC tendem a possuir maior assimetria informacional. Estes resultados geram evidências adicionais aos estudos em cenário brasileiro que rejeitaram a hipótese de que maiores níveis de GC estão relacionados a menor assimetria informacional (ANTUNES; MENDONÇA, 2008; ANTUNES et al., 2013) e assim, coaduna com o previsto pela literatura, de que boas práticas de GC são capazes de reduzir a assimetria informacional (ARMSTRONG; GUAY; WEBER, 2010).

A variável de controle referente ao tamanho das empresas brasileiras, mostrou-se negativamente relacionada à assimetria de informação, tanto ao término de um período (Painel A), como para os períodos posteriores (Painel B e C). Tais resultados podem ser explicados mediante os achados de Mendes-da-Silva e Onusic (2014) que evidenciaram que empresas maiores tendem a divulgar um maior número de informações, assim sendo mais transparentes. Esses achados permitem a compreensão de que quanto maior a empresa, mais transparente ela será, e assim apresentará menor nível de assimetria informacional entre gestores e acionistas.

Ao contrário das evidências obtidas em cenário brasileiro, nas empresas americanas a GC (GC_Geral) não se mostrou significativamente relacionada à assimetria informacional para nenhuma das equações, o que não permite maiores constatações sobre a relação entre a GC - quando analisada de forma abrangente - e a assimetria de informação nos EUA. Portanto, com o intuito de melhor compreender esse resultado em cenário americano, realizou-se uma análise explorando as diferentes dimensões de GC, a qual está apresentada na Tabela 4.

Para empresas americanas, tem-se que o ROE e o endividamento das empresas se mostraram negativamente relacionados com a assimetria de informação nos três períodos (Painel A, B e C). Esta evidência foi também obtida na pesquisa de Silva, Cunha e Teixeira (2017), os quais afirmam que com o intuito de atraírem investidores, as empresas com maiores níveis de dívidas e de rentabilidade tornam suas informações mais transparentes e assim reduzem o nível de assimetria entre as informações dos gestores e dos acionistas.

$\mathrm{Na}$ Tabela 4 estão expostos os resultados da influência de cada dimensão de GC (gestão, acionistas e estratégias) na assimetria informacional. No Painel A, apresentam-se os resultados da equação 4 referentes ao spread no final de um período, no Painel B, apresentam-se os resultados da equação 5 referentes ao spread em 3 meses posteriores ao término de um período e, por fim, no Painel C, apresentam-se os resultados da equação 6 referentes ao spread em 6 meses posteriores ao término de um período.

Tabela 4 - Influência das dimensões de governança corporativa na assimetria de informação

\begin{tabular}{|c|c|c|c|c|c|c|}
\hline \multirow{3}{*}{ Variáveis } & \multicolumn{3}{|c|}{ BRA } & \multicolumn{3}{|c|}{ EUA } \\
\hline & \multicolumn{6}{|c|}{ Equação 4} \\
\hline & Coeficiente & $t$ & VIF & Coeficiente & $t$ & VIF \\
\hline Constante & $0,0269^{*}$ & 3,40 & - & 0,0001 & 0,81 & - \\
\hline GC Ges & $-1,12 \mathrm{e}-$ & $-0,13$ & 2,06 & $-3,37 e^{-*}$ & $-2,04$ & 1,41 \\
\hline GC_Aci & $-7,77 \mathrm{e}-$ & $-1,13$ & 1,62 & $3,89 \mathrm{e}-$ & 0,26 & 1,37 \\
\hline GC Est & $-0,0000^{* *}$ & $-1,90$ & 2,83 & $1,02 \mathrm{e}-$ & 0,41 & 1,56 \\
\hline TAM & $-0,0007^{*}$ & $-2,25$ & 3,23 & 0,0000 & 1,41 & 2,95 \\
\hline ROE & 0,0003 & 0,22 & 1,60 & $-9,25 e^{-*}$ & $-2,33$ & 1,12 \\
\hline END & $-0,0004$ & $-0,31$ & 1,81 & $-0,0000^{\star \star}$ & $-1,68$ & 2,13 \\
\hline Efeito Fixo - Setor & \multicolumn{3}{|c|}{ Sim } & \multicolumn{3}{|c|}{ Sim } \\
\hline Efeito Fixo - Ano & \multicolumn{3}{|c|}{ Sim } & \multicolumn{3}{|c|}{ Sim } \\
\hline $\mathrm{R}^{2}$ & \multicolumn{3}{|c|}{0,2821} & \multicolumn{3}{|c|}{0,3000} \\
\hline ANOVA & \multicolumn{3}{|c|}{$0,0000^{*}$} & \multicolumn{3}{|c|}{$0,0000^{*}$} \\
\hline Durbin Watson & \multicolumn{3}{|c|}{1,7743} & \multicolumn{3}{|c|}{2,1798} \\
\hline Número de observações & \multicolumn{3}{|c|}{390} & \multicolumn{3}{|c|}{472} \\
\hline
\end{tabular}


Tabela 4 - Influência das dimensões de governança corporativa na assimetria de informação Painel B: Assimetria de informação medida pelo spread em 3 meses após o final do período

\begin{tabular}{|c|c|c|c|c|c|c|}
\hline \multirow{3}{*}{ Variáveis } & \multicolumn{3}{|c|}{ BRA } & \multicolumn{3}{|c|}{ EUA } \\
\hline & \multicolumn{6}{|c|}{ Equação 5} \\
\hline & Coeficiente & $t$ & VIF & Coeficiente & $t$ & VIF \\
\hline Constante & $0,0268^{\star}$ & 2,42 & - & 0,0001 & 0,76 & - \\
\hline GC_Ges & $-6,76 e-$ & $-1,39$ & 2.06 & $-3,35 e^{-*}$ & $-2,09$ & 1,41 \\
\hline GC_Aci & $-0,0000^{* *}$ & $-1,68$ & 1.62 & $6,60 \mathrm{e}-$ & 0,44 & 1,37 \\
\hline GC_Est & $-0,0000^{*}$ & $-3,39$ & 2.83 & $3,69 \mathrm{e}-$ & 0,15 & 1,56 \\
\hline TAM & $-0,0004^{*}$ & $-2,33$ & 3.23 & 0,0000 & 1,46 & 2,95 \\
\hline ROE & 0,0007 & 0,47 & 1.60 & $-9,36 e^{*}$ & $-2,44$ & 1,12 \\
\hline END & 0,0012 & 1,40 & 1.81 & $-0,0000^{\star *}$ & $-1,70$ & 2,13 \\
\hline Efeito Fixo - Setor & \multicolumn{3}{|c|}{ Sim } & \multicolumn{3}{|c|}{ Sim } \\
\hline Efeito Fixo - Ano & \multicolumn{3}{|c|}{ Sim } & \multicolumn{3}{|c|}{ Sim } \\
\hline $\mathrm{R}^{2}$ & \multicolumn{3}{|c|}{0,3694} & \multicolumn{3}{|c|}{0.2913} \\
\hline ANOVA & \multicolumn{3}{|c|}{0,0000} & \multicolumn{3}{|c|}{0.0000} \\
\hline Durbin Watson & \multicolumn{3}{|c|}{2,0257} & \multicolumn{3}{|c|}{2,1750} \\
\hline Número de observações & \multicolumn{3}{|c|}{390} & \multicolumn{3}{|c|}{472} \\
\hline \multicolumn{7}{|c|}{ Painel C: Assimetria de informação medida pelo spread em 6 meses após o final do período. } \\
\hline \multirow{3}{*}{ Variáveis } & \multicolumn{3}{|c|}{ BRA } & \multicolumn{3}{|c|}{ EUA } \\
\hline & \multicolumn{6}{|c|}{ Equação 6} \\
\hline & Coeficiente & $t$ & VIF & Coeficiente & $t$ & VIF \\
\hline Constante & $0,0232^{*}$ & 2,90 & - & 0,0001 & 0,72 & - \\
\hline GC_Ges & $-7,00 e^{* \star}$ & -1.88 & 2.06 & $-3,24 e^{-*}$ & $-2,07$ & 1,41 \\
\hline GC_Aci & $-4,80 e^{-}$ & -0.98 & 1.62 & $8,10 \mathrm{e}-$ & 0,56 & 1,37 \\
\hline GC Est & $-0,0000^{*}$ & -3.51 & 2.83 & $1,47 \mathrm{e}-$ & 0,01 & 1,56 \\
\hline TAM & $-0,0004^{*}$ & -3.20 & 3.23 & 0,0000 & 1,51 & 2,95 \\
\hline ROE & $-0,0000$ & $-0,04$ & 1.60 & $-9,52 e^{*}$ & $-2,53$ & 1,12 \\
\hline END & 0,0006 & 0.95 & 1.81 & $-0,0000^{* *}$ & $-1,75$ & 2,13 \\
\hline Efeito Fixo - Setor & \multicolumn{3}{|c|}{ Sim } & \multicolumn{3}{|c|}{ Sim } \\
\hline Efeito Fixo - Ano & \multicolumn{3}{|c|}{ Sim } & \multicolumn{3}{|c|}{ Sim } \\
\hline $\mathrm{R}^{2}$ & \multicolumn{3}{|c|}{0,3694} & \multicolumn{3}{|c|}{0,2873} \\
\hline ANOVA & \multicolumn{3}{|c|}{0,0000} & \multicolumn{3}{|c|}{0,0000} \\
\hline Durbin Watson & & & & & & \\
\hline Número de observações & & & & & & \\
\hline
\end{tabular}

Legenda: * Significância a nível de 5\%; ** Significância a nível de 10\%; BRA: Brasil, EUA: Estados Unidos, t: Estatística t, VIF: Variance Inflation Factor, TAM: Tamanho, ROE: Rentabilidade sobre o Patrimônio líquido, END: Endividamento; Como as dimensões de GC (gestão, acionistas e estratégias) não apresentaram problemas de multicolineariedade (VIF abaixo de 10 em todos os casos), foram operacionalizadas na mesma regressão.

Fonte: Elaborado pelos autores.

A análise sobre as diferentes dimensões de GC permite a compreensão sobre quais práticas especificamente são capazes de influenciar na assimetria informacional em cada um dos países investigados, visto que de acordo com Gillan (2006), podem existir diferenças na GC presente em diferentes contextos. Ressalta-se que os modelos econométricos apresentam significância no teste ANOVA, o que permite a realização de inferências acerca dos resultados e além disso, não se mostraram expostos a problemas graves de multicolinearidade (VIF menor do que 10) nem tampouco de auto correlação dos resíduos (Durbin Watson próximo a 2).

Observa-se que para as empresas brasileiras, a dimensão que mede as estratégias em integrar questões econômicas, sociais e ambientais a tomada de decisão, se mostrou negativamente relacionada com a assimetria de informação. Percebe-se mediante a estatística $t$ dos Painéis $\mathrm{A}, \mathrm{B}$ e $\mathrm{C}$, que essa dimensão de GC se mostrou mais fortemente relacionada a assimetria, em meses posteriores ao final de um período (Painel $B$ e C).

A dimensão de GC relacionada aos acionistas se mostrou negativamente relacionada somente com a assimetria de informação medida após 3 meses ao término de um período (Painel B). Esta evidência foi encontrada recentemente no estudo brasileiro de Rodrigues e Galdi (2017), que constataram que as atividades de relação com investidores (métrica relacionada aos acionistas) são capazes de minimizar a assimetria de informação.

A dimensão de GC relacionada à gestão se mostrou negativamente relacionada com a assimetria de informação medida após 6 meses ao término de um período (Painel C), o que corrobora com os resultados de Silva, Cunha e Teixeira (2017), que encontraram relação negativa entre assimetria de informação e o tamanho do conselho de administração, a independência e a expertise do conselho, quando mediram o spread em 3 e 6 meses após o término de um período. No estudo de Silva, Cunha e Teixeira (2017) o foco foi dado ao conselho de administração e as suas características, enquanto que no presente estudo, itens relacionados ao conselho de administração estão inseridos na dimensão de GC relacionada à gestão. 
Em suma, em empresas brasileiras as práticas de GC relacionadas especificamente à integração de questões econômicas, sociais e ambientais à tomada de decisão (medidas por itens que avaliam se a empresa divulga relatório baseado nas diretrizes do GRI, se possui auditoria externa para as atividades sustentáveis, entre outros quesitos) se mostraram negativamente relacionadas à assimetria de informação em todos os períodos. Com relação às práticas de GC baseadas na gestão e acionistas, verificou-se que apenas em meses subsequentes ao término de um período estas apresentam reflexo na assimetria informacional.

Com relação as empresas americanas, verifica-se um comportamento padrão com relação à GC relacionada a gestão, que se demonstrou negativamente relacionada a assimetria de informação para todas as medidas de Spread. Esta evidência sugere que empresas americanas que possuem um comitê de auditoria, um comitê de auditoria com características de independência e expertise, um conselho de administração definido por características com relação ao seu tamanho, independência, expertise, número de mulheres, entre outros atributos relacionados a forma da gestão lidar com problemas de agência percebidos nas empresas, são mais propensas a terem menor assimetria informacional.

Portanto, essa segunda parte da análise pode explicar os motivos pelos quais, quando investigadas as dimensões de GC de maneira agregada (GC_Geral) nas empresas americanas, a variável não apresentou relação significativa com a assimetria informacional. Para as empresas americanas, somente à dimensão de gestão é um determinante da redução da assimetria informacional, excluindo-se as práticas direcionadas aos acionistas e as estratégias da empresa em integrar questões econômicas, sociais e ambientais.

De maneira geral, os resultados evidenciaram uma relação negativa entre GC e a assimetria informacional, o que suporta a hipótese proposta nesta pesquisa e reafirmam a premissa de Gillan (2006) de que práticas de GC possuem diferentes papeis em contextos de países. Mais especificamente, para as empresas brasileiras, as práticas de GC direcionadas às estratégias pode ser percebida como um determinante para a minimização da assimetria informacional, enquanto que para as americanas, a GC direcionada à gestão é um determinante para a redução da assimetria informacional. De acordo com Gillan (2006), essas diferenças podem ser atribuídas aos fatores sociais, econômicos e culturais, que acabam influenciam a necessidade de diferentes dimensões de GC.

Com base nessas evidências, salienta-se que é necessário cautela ao analisar diferentes práticas de GC em diferentes contextos, uma vez que a eficácia dos mecanismos de controle em alinhar interesses e minimizar o contexto de informações assimétricas pode ser diferente em cada contexto.

\section{Conclusões}

Essa pesquisa objetivou analisar a influência da GC na assimetria de informação em empresas brasileiras e americanas. Para tanto, utilizou-se de procedimento descritivo, documental e quantitativo, em uma amostra de 81 empresas brasileiras listadas no índice Ibrx100 e 98 empresas americanas listadas no índice S\&P100. A separação da amostra entre empresas brasileiras e americanas foi realizada com o intuito de comparar empresas advindas de um país economicamente emergente (Brasil) e desenvolvido (EUA).

Notou-se que, com base nos resultados obtidos, empresas americanas possuem menor assimetria informacional do que empresas brasileiras e que empresas americanas possuem maiores níveis de GC, representando uma diferença de $70 \%$ maior do que empresas brasileiras. Com relação ao objetivo proposto, observou-se que mecanismos integrados de GC possuem influência negativa na assimetria de informação em cenário brasileiro, apresentando-se como um determinante para a redução de assimetria informacional. Todavia, em cenário americano, a GC percebida de maneira integrada não apresentou relação estatisticamente significante com a assimetria de informação em nenhuma das condições temporais analisadas.

Para melhor compreender os resultados obtidos em empresas americanas, as três dimensões de GC (gestão, acionistas e estratégias) foram analisadas como variáveis independentes. Dessa forma, percebeuse que a variável de GC direcionada a gestão se mostrou estatisticamente significante e negativamente relacionada à assimetria informacional nos três períodos de spread analisados. Portanto, percebe-se que em cenário americano, os mecanismos de gestão podem ser considerados determinantes capazes de minimizar a assimetria informacional, reduzindo assim o conflito de agência nessas empresas.

Em cenário brasileiro, ao analisar as dimensões de GC isoladamente, notou-se que a dimensão direcionada às estratégias empresariais em integrar questões sociais, econômicas e ambientais à tomada de decisões, se mostrou negativamente relacionada com à assimetria informacional nos três períodos de spread analisados. Ademais, as variáveis de GC direcionadas aos acionistas e a gestão, se mostraram negativamente relacionadas com o spread de 3 e 6 meses após o término de um período, respectivamente.

De maneira geral, a contribuição dessa pesquisa está voltada as evidências empíricas de que a GC pode ser percebida como um determinante para a minimização da assimetria informacional, representando desta forma, um mecanismo responsável por auxiliar no alinhamento de interesses entre gestores e acionistas. Todavia, deve-se atentar para o fato de que diferentes mecanismos de GC podem influenciar de maneira diferente na minimização da assimetria informacional, sendo que, questões sociais, econômicas e ambientais podem impactar nessa relação, quando se observa diferentes países. 
Por isso, as diferentes relações evidenciadas entre empresas americanas e brasileiras representam a possibilidade de que nesses diferentes contextos, as organizações estejam enfrentando diferentes problemas de agência, uma vez que nos EUA as melhores práticas de GC implantadas na organização possuem como finalidade alinhar interesses entre gestores e acionistas, enquanto que no Brasil, 0 alinhamento é voltado para usuários externos, em que organizações utilizam práticas com o intuito de comunicar e integrar dimensões econômicas, sociais e ambientais para minimizar informações assimétricas.

Ainda, contribui-se no sentido de prover evidências para empresas de que investir em práticas de GC gera benefícios relacionais para com as partes interessadas, ou seja, propicia aos stakeholders informações mais transparentes sobre a realidade da organização. Ressalta-se ainda, que os stakeholders devem observar as diferenças a nível de país que fazem com que empresas invistam em distintos mecanismos de GC, considerando que em cada nação a assimetria de informação pode ser reduzida mediante mecanismos voltados para a gestão, para os acionistas ou ainda, para estratégias de integração na tomada de decisões. Por fim, contribui-se no sentido de prover indícios sobre a GC mediante a utilização de métricas que captam diferentes mecanismos e que são medidas padronizadas, adotadas por empresas de todo o mundo e disponibilizadas pela base de dados internacional Thomson Reuters Eikon.

Algumas limitações, contudo, estão presentes nessa pesquisa. Inicialmente, destaca-se que a análise foi realizada somente em uma amostra das 100 maiores empresas de cada país, o que limita os resultados para essas empresas. Portanto, como recomendações, sugere-se que pesquisas futuras considerem uma amostra mais ampla de análise. Além disso, não foram consideradas questões a nível de país, como questões sociais e culturais, que podem ser possíveis variáveis de influência na relação de GC e assimetria informacional.

\section{Referências}

AKERLOF, G. A. The market for "lemons": Quality uncertainty and the market mechanism. Uncertainty in Economics. v. 84, n. 3, p. 235-251, 1978. DOI: https://doi.org/10.1016/B978-0-12-214850-7.50022-X

ALBANEZ, T.; VALLE, M. R. Impactos da assimetria de informação na estrutura de capital de empresas brasileiras abertas. Revista Contabilidade \& Finanças, v. 20, n. 51, p. 6-27, 2009. DOI: https://doi.org/10.1590/S1519-70772009000300002

ANTUNES, G. A.; MENDONÇA, M. M. Impacto da adesão aos níveis de governança da BOVESPA na qualidade da informação contábil: uma investigação acerca da oportunidade, relevância e do conservadorismo contábil utilizando dados em painel. In: Congresso da Associação Nacional dos Programas de Pós-graduação em Ciências Contábeis. 2008. Anais..., 2008.

ANTUNES, G. A.; TEIXEIRA, A. J. C. D.; COSTA, F. M. D; NOSSA, V. Efeitos da adesão aos níveis de governança da Bolsa de Valores de São Paulo na qualidade da informação contábil. ASAA-Advances in Scientific and Applied Accounting, v. 3, n. 1, p. 109-138, 2013.

ANUCHITWORAWONG, C. The value of principles-based governance practices and the attenuation of information asymmetry. Asia-Pacific Financial Markets, v. 17, n. 2, p. 171-207, 2010. DOI: http://dx.doi.org/10.1007/s10690-010-9114-4

ARMSTRONG, C. S.; GUAY, W. R.; WEBER, J. P. The role of information and financial reporting in corporate governance and debt contracting. Journal of Accounting and Economics, v. 50, n. 2-3, p. 179234, 2010. DOI: https://doi.org/10.1016/j.jacceco.2010.10.001

ARMSTRONG, C. S.; BALAKRISHNAN, K.; COHEN, D. Corporate governance and the information environment: Evidence from state antitakeover laws. Journal of Accounting and Economics, v.53, n.1-2, p.185-204, 2012. DOI: http://dx.doi.org/10.1016/j.jacceco.2011.06.005

BARBEDO, C. H.; SILVA, E. C.; LEAL, R. P. C. Probabilidade de informação privilegiada no mercado de ações, liquidez intra-diária e níveis de governança corporativa. Revista Brasileira de Economia, v. 63, n. 1, p. 51-62, 2009. DOI: https://doi.org/10.1590/S0034-71402009000100004

BERLE, Adolph; MEANS, Gardiner. Private property and the modern corporation. New York: Mac-millan, 1932.

BUSHMAN, Robert M.; SMITH, Abbie J. Transparency, financial accounting information, and corporate governance. Economic Policy Review, v. 9, n. 1, p. 65-87, 2003. 
CHANG, J. C.; SUN, H. L. Crossed-listed foreign firms' earnings informativeness, earnings management and disclosures of corporate governance information under SOX. The International Journal of Accounting, $v$. 44, n. 1, p. 1-32, 2009. DOI: https://doi.org/10.1016/j.intacc.2008.12.004

DOYLE, J.; GE, W.; MCVAY, S. Determinants of weaknesses in internal control over financial reporting. Journal of Accounting and Economics, v. 44, n. 1-2, p. 193-223, 2007. DOI: https://doi.org/10.1016/j.jacceco.2006.10.003

ELFEKY, M. I. The extent of voluntary disclosure and its determinants in emerging markets: Evidence from Egypt. The Journal of Finance and Data Science, v. 3, n. 1-4, p. 45-59, 2017. DOI: https://doi.org/10.1016/j.jfds.2017.09.005

FAUVER, L.; NARANJO, A. Derivative usage and firm value: The influence of agency costs and monitoring problems. Journal of Corporate Finance, v. 16, n. 5, p. 719-735, 2010. DOI:

http://dx.doi.org/10.1016/j.jcorpfin.2010.09.001

GILLAN, S. L. Recent developments in corporate governance: An overview. Journal of Corporate Finance, v. 12, n.1, p. 381-402, 2006. DOI: http://dx.doi.org/10.1016/j.jcorpfin.2005.11.002

INSTITUTO BRASILEIRO DE GOVERNANÇA CORPORATIVA. Código das melhores práticas de governança corporativa. São Paulo, 2015.

JENSEN, M. C.; MECKLING, W. H. Theory of the firm: Managerial behavior, agency costs and ownership structure. Journal of Financial Economics, v. 3, n. 4, p. 305-360, 1976. DOI: https://doi.org/10.1007/97894-009-9257-3_8

JIANG, H.; HABIB, A.; HU, Baiding. Ownership concentration, voluntary disclosures and information asymmetry in New Zealand. The British Accounting Review, v. 43, n. 1, p. 39-53, 2011. DOI: https://doi.org/10.1016/j.bar.2010.10.005

KANAGARETNAM, K.; LOBO, G. J.; WHALEN, D. J. Does good corporate governance reduce information asymmetry around quarterly earnings announcements? Journal of Accounting and Public Policy, v. 26, $n$. 4, p. 497-522, 2007. DOI: http://dx.doi.org/10.1016/j.jaccpubpol.2007.05.003

KLAPPER, L.; LOVE, I. Corporate governance, investor protection and performance in emerging markets. Journal of Corporate Finance, v.10, n.5, p.703-728, 2004. DOI: http://dx.doi.org/10.1016/S09291199(03)00046-4

LA PORTA, R.; LOPEZ-DE-SILANES, F.; SHLEIFER, A.; VISHNY, R. Investor protection and corporate valuation. Journal of Finance, v.57, n.3, p.1147-1170, 2002. DOI: http://dx.doi.org/10.1111/15406261.00457

LI, Y.; GONG, M.; ZHANG, X. Y.; KOH, L. The impact of environmental, social, and governance disclosure on firm value: The role of CEO power. The British Accounting Review, v. 50, n. 1, p. 60-75, 2018. DOI: https://doi.org/10.1016/j.bar.2017.09.007

MARTINS, O. S.; PAULO, E. Information asymmetry in stock trading, economic and financial characteristics and corporate governance in the Brazilian stock market. Revista Contabilidade \& Finanças, v. 25, n. 64, p. 33-45, 2014. DOI: https://doi.org/10.1590/S1519-70772014000100004

MENDES-DA-SILVA, W.; ONUSIC, L. M. Corporate e-disclosure determinants: evidence from the Brazilian market. International Journal of Disclosure and Governance, v. 11, n. 1, p. 54-73, 2014. DOI: https://doi.org/10.1057/jdg.2012.14

MENSI, W.; HAMMOUDEH, S.; YOON, S. M.; NGUYEN, D. K. Asymmetric linkages between BRICS stock returns and country risk ratings: evidence from dynamic panel threshold models. Review of International Economics, v. 24, n. 1, p. 1-19, 2016. DOI: https://doi.org/10.1111/roie.12201

MOREIRAS, L. M. F. Os efeitos da governança corporativa sobre a informação assimétrica. Tese (Doutorado em Administração de Empresas) - Fundação Getúlio Vargas, São Paulo, 2010.

OLIVEIRA, K. P. S.; PAULO, E.; MARTINS, O. S. As relações entre a assimetria de informação e a governança corporativa no mercado de capitais brasileiro. Registro Contábil, v. 4, n. 3, p. 56-70, 2013. 
OLIVEIRA, M. C.; ARAÚJO JUNIOR, J. F.; OLIVEIRA, O. V.; PONTE, V. M. R. Disclosure social de empresas brasileiras e britânicas à luz da teoria institucional. ASAA-Advances in Scientific and Applied Accounting, v. 5, n. 1, p. 2-26, 2013.

PIRES, C. O.; MACAGNAN, C. B. Governança corporativa e assimetria de informação: uma revisão desta relação. Revista Brasileira de Administração Científica, v. 4, n. 4, p. 80-94, 2013. DOI: https://doi.org/10.6008/ESS2179-684X.2013.004.0005

RABELO, F. M.; VASCONCELOS, F. C. Corporate governance in Brazil. Journal of Business Ethics, v. 37, n. 3, p. 321-335, 2002. DOI: https://doi.org/10.1023/A:1015249300794

REZENDE, C. V.; ALMEIDA, N. S.; LEMES, S. Impacto das IFRS na assimetria de informação evidenciada no mercado de capitais brasileiro. Revista de Contabilidade e Organizações, v. 9, n. 24, p. 18-30, 2015. DOI: http://dx.doi.org/10.11606/rco.v9i24.55524

RODRIGUES, S. S.; GALDI, F. C. Relações com investidores e assimetria informacional. Revista Contabilidade \& Finanças, v. 28, n. 74, p. 297-312, 2017. DOI: https://doi.org/10.1590/1808$057 \times 201703630$

SHEIKH, A. N.; WANG, Z. Effects of corporate governance on capital structure: empirical evidence from Pakistan. Corporate Governance: The international journal of business in society, v. 12, n. 5, p. 629641, 2012. DOI: https://doi.org/10.1108/14720701211275569

SHLEIFER, A.; VISHNY, R. W. A survey of corporate governance. The Journal of Finance, v. 52, n. 2, p. 737-783, 1997. DOI: http://dx.doi.org/10.1016/j.jaccpubpol.2007.05.003

SILVA, A.; CUNHA, P. R.; TEIXEIRA, S. A. Características do comitê de auditoria e deficiências do controle interno: análise de empresas brasileiras. In: Seminário em Administração, São Paulo, 2017. Anais..., 2017.

SILVEIRA, A. D. M. Governança corporativa e estrutura de propriedade: determinantes e relação com o desempenho das empresas no Brasil. Tese (Doutorado em Administração) - Curso de Pós-Graduação em Administração, Faculdade de Economia, Administração Contabilidade, Universidade de São Paulo, São Paulo, 2004.

VIANA JÚNIOR, D. B. C.; PONTE, V. M. R. Políticas de dividendos: um estudo comparativo entre empresas brasileiras e norte-americanas. Revista Universo Contábil, v. 12, n. 1, p. 25-44, 2016. DOI:

10.4270/ruc.2016102

VIEIRA, S. P.; MENDES, A. G. S. T. Governança corporativa: uma análise de sua evolução e impactos no mercado de capitais brasileiro. Revista do BNDES, v. 11, n.22, p-103-122, 2004.

\section{NOTAS}

\section{AGRADECIMENTOS}

As contribuições recebidas no Congresso EnANPAD de 2018.

\section{CONTRIBUIÇÃO DE AUTORIA}

Concepção e elaboração do manuscrito: C. K. Soschinski, D. Schlup, N. M. Bogoni, P. R. Cunha

Coleta de dados: C. K. Soschinski

Análise de dados: D. Schlup

Discussão dos resultados: N. M. Bogoni

Revisão e aprovação: P. R. Cunha

\section{CONJUNTO DE DADOS DE PESQUISA}

O conjunto de dados que dá suporte aos resultados deste estudo não está disponível publicamente.

\section{FINANCIAMENTO}

O presente trabalho foi realizado com apoio da Coordenação de Aperfeiçoamento de Pessoal de Nível Superior - Brasil (CAPES) - Código de Financiamento 001.

CNPq - Conselho Nacional de Desenvolvimento Científico e Tecnológico projeto 308252/2016-0. 


\section{CONSENTIMENTO DE USO DE IMAGEM}

Não se aplica.

\section{APROVAÇÃO DE COMITÊ DE ÉTICA EM PESQUISA \\ Não se aplica.}

\section{CONFLITO DE INTERESSES}

Não se aplica.

\section{LICENÇA DE USO}

Os Direitos Autorais para artigos publicados neste periódico são do autor, com direitos de primeira publicação para a Revista. Em virtude de aparecerem nesta Revista de acesso público, os artigos são de uso gratuito, com atribuições próprias, em aplicações educacionais, de exercício profissional e para gestão pública. A Revista adotou a licença Creative Commons Atribuição 4.0 Internacional - CC BY NC ND. Esta licença permite acessar, baixar (download), copiar, imprimir, compartilhar, reutilizar e distribuir os artigos desde que com a citação da fonte, atribuindo os devidos créditos de autoria. Nesses casos, nenhuma permissão é necessária por parte dos autores ou dos editores. Autores têm autorização para assumir contratos adicionais separadamente, para distribuição não-exclusiva da versão do trabalho publicada nesta revista (ex.: publicar em repositório institucional ou um capítulo de livro).

\section{PUBLISHER}

Universidade Federal de Santa Catarina. Curso de Ciências Contábeis e Programa de Pós-graduação em Contabilidade. Publicação no Portal de Periódicos UFSC. As ideias expressadas neste artigo são de responsabilidade de seus autores, não representando, necessariamente, a opinião dos editores ou da universidade.

\section{EDITORES}

Carlos Eduardo Facin Lavarda e Suliani Rover

\section{HISTÓRICO}

Recebido em: 03/09/2019 - Revisado por pares em: 21/05/2019 - Reformulado em: 10/06/2020 Recomendado para publicação em: 11/06/2020 - Publicado em: 30/06/2020

Uma versão preprint do artigo foi apresentada no Congresso EnANPAD, 2018. 